\title{
Optimizing a sustainable ultrasound assisted extraction method for the recovery of polyphenols from lemon by-products: comparison with hot water and organic solvent extractions
}

Konstantinos Papoutsis

Penta Pristijono John B. Golding

Costas E. Stathopoulos Michael C. Bowyer

Christopher J. Scarlett

Quan V. Vuong

This is a post-peer-review, pre-copyedit version of an article published in European Food Research and Technology. The final authenticated version is available online at:

http://dx.doi.org/10.1007/s00217-018-3049-9 
1 Optimizing a sustainable ultrasound-assisted extraction method for the recovery of

2 polyphenols from lemon by-products: Comparison with hot water and organic solvent extractions

4

5 Konstantinos Papoutsis ${ }^{1, *}$, Penta Pristijono ${ }^{1}$, John B. Golding ${ }^{1,2}$, Costas E. Stathopoulos ${ }^{3}$,

6 Michael C. Bowyer ${ }^{1}$, Christopher J. Scarlett ${ }^{1}$, Quan V. Vuong ${ }^{1}$

7

$8{ }^{1}$ School of Environmental and Life Sciences, The University of Newcastle PO Box 127

9 Ourimbah, NSW 2258, Australia

$10 \quad{ }^{2}$ NSW Department of Primary Industries, Locked Bag 26 Gosford, NSW 2250, Australia

$11{ }^{3}$ Division of Food and Drink School of Science, Engineering and Technology University of

12 Abertay Dundee DD1 1HG UK

13

*Corresponding author: Konstantinos Papoutsis; e-mail address:

Konstantinos.Papoutsis@uon.edu.au. 


\section{Abstract}

Response surface methodology (RSM) based on a three-factor and three-level BoxBehnken design was employed for optimizing the aqueous ultrasound-assisted extraction (AUAE) conditions, including extraction time (35-45 min), extraction temperature $\left(45-55^{\circ} \mathrm{C}\right)$ and ultrasonic power $(150-250 \mathrm{~W})$, for the recovery of total phenolic content (TPC) and rutin from lemon by-products. The independent variables and their values were selected on the basis of preliminary experiments, where the effects of five extraction parameters (particle size, extraction time and temperature, ultrasonic power and sample-to-solvent ratio) on TPC and rutin extraction yields were investigated. The yields of TPC and rutin were studied using a second-order polynomial equation. The optimum AUAE conditions for TPC were extraction time of $45 \mathrm{~min}$, extraction temperature of $50^{\circ} \mathrm{C}$ and ultrasonic power of $250 \mathrm{~W}$ with a predicted value of $18.10 \pm 0.24 \mathrm{mg} \mathrm{GAE} / \mathrm{g} \mathrm{dw}$, while the optimum AUAE conditions for rutin were extraction time of $35 \mathrm{~min}$, extraction temperature of $48^{\circ} \mathrm{C}$ and ultrasonic power of $150 \mathrm{~W}$ with a predicted value of $3.20 \pm 0.12 \mathrm{mg} / \mathrm{g} \mathrm{dw}$. The extracts obtained at the optimum AUAE conditions were compared with those obtained by a hot water and an organic solvent conventional extraction in terms of TPC, total flavonoid content (TF) and antioxidant capacity. The extracts obtained by AUAE had the same TPC, TF and ferric reducing antioxidant power as those achieved by organic solvent conventional extraction. However, hot water extraction led to extracts with the highest flavonoid content and antioxidant capacity. Scanning electron microscopy analysis showed that all the extraction methods led to a cell damage to varying extents.

Keywords: citrus peels; polyphenols; ultrasound; antioxidant capacity; advanced extraction; flavonoids 


\section{Introduction}

Citrus is one of the most important horticultural crops in the world, with a worldwide production exceeding 121 million tons (Data 2013/14) [1]. Juice industry uses about 34\% of citrus production and high amounts of by-products are generated during this procedure. Peel and seed residues are the main by-product and may account for up to $50 \%$ of the total fruit weight [2]. Citrus peel has been shown to be a good source of phenolic compounds, including phenolic acids and flavonoids (flavanones, flavones, and flavonols) [3], which have been linked to antiradical activities (in vitro) [4], antifungal activities against plant pathogens (in vivo and in vitro) [5,6], as well as anticancer activities (in vivo and in vitro) [7].

Rutin (quercetin-3-O-rutinoside) is a flavonoid glucoside which is found in lemon rinds [3]. Rutin is a compound of a high commercial value due to its potential health benefits. In vitro experiments have shown that rutin exhibits antiradical activity and may inhibit lipid peroxidation [8], while in vivo experiments in rats revealed the protective effects of rutin against histopathological changes of kidney induced by chemotherapeutic agents [9].

Extraction is the first step in the recovery of polyphenols with the solvent type being considered as one of the most important parameters affecting their recovery [10]. Organic solvents, including methanol, ethanol, acetone and their mixtures with water are commonly used for the recovery of polyphenols from citrus wastes [3]. However, their use should be reconsidered due to their high toxicity which negatively affects human health and environment. Water should be considered as an alternative solution, however, it can lead to lower polyphenol recovery yields compared to those obtained by organic solvents [11]. The greater polyphenol extraction yields obtained by the use of organic solvents have been attributed to their polar organic character which successfully solvates a wide range of compounds and their ability to limit polyphenol oxidase (PPO) activity which is an enzyme responsible for the oxidation of phenolic compounds [12]. 
Phenolic compounds are confined to the plant vacuole, thereby their recovery yields are promoted by the disruption of cell walls of the plant matrix [13]. Ultrasound-assisted extraction is considered as an advanced extraction technique, leading to high recovery yields of bioactive compounds due to cavitation, which causes the breakdown of cell walls, improving diffusion rates [14]. However, during ultrasound extraction process a considerable amount of polyphenols might be degraded due to undesirable extraction conditions (extraction time, extraction temperature, ultrasonic power, etc.), resulting in the loss of polyphenol beneficial properties $[15,16]$. Therefore, by optimizing the ultrasound extraction conditions, high-quality polyphenol extracts could be obtained for further utilization.

Optimization can be performed either by examining the effect of one factor at a time on a dependent variable (known as one-variable-at-a-time technique) or by using multivariate statistical techniques, such as response surface methodology (RSM) $[17,18]$. RSM is used for optimizing the levels of different parameters at the same time, offering information about interaction or quadratic effects of the independent variables on the dependent variables [19,20]. The aims of this study were to: i) investigate the effect of different ultrasonic parameters (particle size, extraction temperature and time, ultrasonic power and sample-to-solvent ratio) on the recovery yields of total phenolic content (TPC) and rutin from lemon by-products, ii) optimize the aqueous ultrasonic assisted extraction conditions for the recovery of TPC and rutin using RSM, iii) compare the polyphenol content and antioxidant capacity of the extracts obtained by the optimized aqueous ultrasound-assisted extraction conditions (AUAE), with those obtained by an optimized hot water extraction method [21] and an organic solvent conventional extraction method [4] in terms of TPC, total flavonoid content (TF), as well as antioxidant capacity, and iv) provide information about cell damage as a result of the different extraction methods. 
Chemicals

All chemicals were of analytical grade. Folin-Ciocalteu phenol reagent, sodium carbonate $\left(\mathrm{Na}_{2} \mathrm{CO}_{3}\right)$ anhydrous, sodium nitrite $\left(\mathrm{NaNO}_{2}\right)$, hydrochloric acid $(\mathrm{HCl})$, ferric chloride $\left(\mathrm{FeCl}_{3}\right)$, gallic acid, catechin, rutin, formic acid, copper (II) chloride $\left(\mathrm{CuCl}_{2}\right)$, ammonium acetate $\left(\mathrm{NH}_{4} \mathrm{Ac}\right)$, neocuproine, 2,4,6-tris(2-pyridyl)-s-triazine (TPTZ), $( \pm)$-6hydroxy-2,5,7,8-tetramethylchromane-2-carboxylic acid (Trolox), 2,2-diphenyl-1picrylhydrazyl (DPPH) were purchased from Sigma-Aldrich Pty Ltd (Castle Hill, Sydney, Australia). Aluminium chloride $\left(\mathrm{Al}_{2} \mathrm{Cl}_{3} \cdot 6 \mathrm{H}_{2} \mathrm{O}\right)$ was obtained from J. T. Baker Chem. Co. (Zedelgem, Belgium). Sodium hydroxide $(\mathrm{NaOH})$ was purchased from Ajax Chem. (NSW, Australia). Sodium acetate trihydrate $\left(\mathrm{CH}_{3} \mathrm{COONa} \cdot 3 \mathrm{H}_{2} \mathrm{O}\right)$ was purchased from Government Stores Department (Sydney, Australia). Glacial acetic acid was obtained from BDH Laboratory Supplies (Poole, UK). Methanol, ethanol and acetonitrile were purchased from Merck (Darmstadt, Germany).

\section{Materials}

Lemon (Citrus limon L.) by-products, including endocarp residual membranes, seeds, and exocarp, was kindly provided by Eastcoast Beverages, a commercial juicing manufacturer in Kulnura, NSW, Australia. After seed removal, the remaining waste with a moisture content of $85 \% \pm 1 \%$ (mean \pm standard deviation) was stored at $-18{ }^{\circ} \mathrm{C}$ until use. Lemon by-products were dried by freeze-drying for 48 h (FD3 freeze dryer; Thomas Australia Pty. Ltd., Seven Hills, Australia) [22]. The dried by-products was ground using a commercial blender (Waring 2-speed blender, John Morris Scientific, Chatswood, Australia) and sieved using steel mesh sieves of three different sizes (1.40, 2.00, $2.80 \mathrm{~mm}$ ) (EFL 2000; Endecotts Ltd., London, England). The ground lemon waste was then sealed and stored at $-18{ }^{\circ} \mathrm{C}$ for further analysis. 
The water activity $\left(\mathrm{a}_{\mathrm{w}}\right)$ of the dried lemon waste was $0.17 \pm 0.01$ (mean \pm standard deviation) at $23.2{ }^{\circ} \mathrm{C}$ and the residual moisture content was $7.6 \% \pm 0.6 \%$ (mean \pm standard deviation).

\section{Experimental design}

Before optimizing the AUAE conditions, the effects of five individual parameters (particle size of sample, extraction time, extraction temperature, ultrasonic power and sampleto-solvent ratio), on the recovery yields of total phenolic content (TPC) and rutin were investigated. When one parameter was examined, the others were kept constant (Fig. 1). For eliminating some of the independent parameters from the design, thus to reduce the number of experimental points, the particle size of $1.40 \mathrm{~mm}$ and the sample-to-solvent ratio of $2 \mathrm{~g} / 100 \mathrm{~mL}$ of water were selected according to the preliminary experiments (Table 1) and a response surface methodology (RSM) using JMP software (version 11) was then applied to design and optimize the AUAE conditions (extraction time, extraction temperature, and ultrasonic power) for the recovery of TPC and rutin. The greater extraction yields obtained during ultrasound extraction have been attributed to the acoustic cavitation phenomena which are affected by the ultrasonic power, the extraction temperature, the extraction time and the frequencies [23]. Therefore, the ultrasonic power, the extraction temperature, and the extraction time were selected to be optimized. RSM is a multivariate strategy offering a large amount of information from a small number of experiments [19]. A three-factor and three-level Box-Behnken design consisting of fifteen experimental runs was employed, including three central points, since Box-Behnken is an economical and efficient design [17]. The linear, quadratic and interaction effects of extraction time $\left(\mathrm{X}_{1}: 35-45 \mathrm{~min}\right)$, extraction temperature $\left(\mathrm{X}_{2}: 45-55^{\circ} \mathrm{C}\right)$ and ultrasonic power $\left(\mathrm{X}_{3}: 150-250 \mathrm{~W}\right)$ were evaluated (Table 2).

The yields of TPC and rutin were studied using a complete second-order polynomial equation (Eq. (1)). 


$$
Y=\beta_{0}+\sum_{i=1}^{n} \beta_{i} X_{i}+\sum_{i=1}^{n} \beta_{i i} X_{i}^{2}+\sum_{j=i+1}^{n} \beta_{i j} X_{i} X_{j} \text { (Eq. (1)) }
$$

where $\mathrm{Y}$ is the predicted response (TPC or rutin), $\beta_{0}$ is the constant term, $\beta_{i}, \beta_{i i}$ and $\beta_{i j}$ represent the coefficients of the linear, quadratic and interaction effects, respectively, whereas $\mathrm{X}_{\mathrm{i}}$ and $\mathrm{X}_{\mathrm{j}}$ are the independent variables [19].

The fit of the model was evaluated by $\mathrm{R}^{2}, P$-value of the model, lack of fit and root mean squared error (RMSE). The validation of the model was performed by applying the optimized extraction conditions of the independent variables and comparing them with the predicted values.

The AUAE method was compared with an optimized hot water extraction (HWE) method [21] and an organic solvent conventional extraction (OSCE) method [4], in terms of TPC, TF, and antioxidant capacity.

\section{Extraction process}

\section{Aqueous ultrasound-assisted extraction (AUAE)}

The (AUAE) of phenolic compounds was conducted by using a $20 \mathrm{~L}$ ultrasonic bath operating at a frequency of $43 \mathrm{kHz} \pm 2 \mathrm{kHz}$ (Soniclean, Soniclean Pty Ltd., Thebarton, Australia). Distilled water was used as a solvent.

\section{Hot water extraction (HWE)}

The optimized extraction procedure described by Papoutsis et al. [21] was employed, with some modifications. Briefly, dried lemon by-product $(1 \mathrm{~g})$ was mixed with $100 \mathrm{~mL}$ of distilled water and placed in a water bath (Labec Laboratory equipment Pty. Ltd., Marrickville, NSW, Australia) at $95^{\circ} \mathrm{C}$ for $15 \mathrm{~min}$. During extraction, the tubes were wrapped with parafilm and aluminum foil for minimizing evaporation. After extraction, the extracts were filtered at ambient temperature using Whatman filter paper number 1. 


\section{Organic solvent conventional extraction (OSCE)}

The extraction was performed at ambient temperature for $1 \mathrm{~h}$. Briefly, dried lemon byproduct $(3 \mathrm{~g})$ was mixed with $30 \mathrm{~mL}$ of $50 \%(\mathrm{v} / \mathrm{v})$ ethanol and left at ambient temperature for $1 \mathrm{~h}$ [4]. After extraction, the extracts were filtered using Whatman filter paper number 1.

\section{Phytochemical analysis}

\section{Total phenolic content (TPC)}

TPC was determined according to Papoutsis et al. [21]. Briefly, $5 \mathrm{~mL}$ of $10 \%$ (v/v) FolinCiocalteu reagent were mixed with $1 \mathrm{~mL}$ of sample. After 3 minutes incubation, $4 \mathrm{~mL}$ of $7.5 \%$ $(\mathrm{w} / \mathrm{v}) \mathrm{Na}_{2} \mathrm{CO}_{3}$, were added to the mixture and incubated in the dark at room temperature for 1

h. The absorbance of the solution was measured at $760 \mathrm{~nm}$ using a UV spectrophotometer (Varian Australia Pty. Ltd., Vic., Melbourne, Australia). The results were expressed as mg of gallic acid equivalents per g of sample dry weight (mg GAE/g dw).

\section{Total flavonoid content (TF)}

TF was determined according to Papoutsis et al. [21]. Briefly, $0.5 \mathrm{~mL}$ of sample was mixed with $2 \mathrm{~mL}$ of $\mathrm{H}_{2} \mathrm{O}$ and $0.15 \mathrm{~mL}$ of $5 \%(\mathrm{w} / \mathrm{v}) \mathrm{NaNO}_{2}$ and incubated at room temperature for $6 \mathrm{~min}$. Then, $0.15 \mathrm{~mL}$ of $10 \%(\mathrm{w} / \mathrm{v}) \mathrm{AlCl}_{3}$ was added and left at room temperature for 6 min. Subsequently, $2 \mathrm{~mL}$ of $4 \%(\mathrm{w} / \mathrm{v}) \mathrm{NaOH}$ and $0.7 \mathrm{~mL}$ of $\mathrm{H}_{2} \mathrm{O}$ were added and the mixture was left at room temperature for further $15 \mathrm{~min}$. The absorbance was measured at $510 \mathrm{~nm}$ using a UV spectrophotometer (Varian Australia Pty. Ltd., Vic., Melbourne, Australia) and the results were expressed as mg of catechin equivalents per g of sample dry weight (mg CE/g dw).

\section{Rutin determination}


The determination of rutin was performed by using high-performance liquid

202

203

204

205

206

207

208

209

210

211

212

213

214

215

216

217

218

219

220

221

222

223

224

chromatography (HPLC) (Shimadzu LC-20AD, Rydalmere, NSW, Australia). A photodiode array detector (Shimadzu SPD-M20A, Rydalmere, NSW, Australia) was employed for the detection. Before HPLC analysis, standards and samples were filtrated through a $0.45 \mu$ m nylon filter. $\mathrm{C}_{18}$ reversed-phase column (Gemini 110A $5 \mu \mathrm{m}, 150 \times 4.6 \mathrm{~mm}$ Phenomenex Australia Pty., Ltd., Lane Cove, NSW, Australia) supplied with a guard column (Gemini $\mathrm{C}_{18}, 4 \times 3.0$ $\mathrm{mm}$ ) was used and the injection volume for samples and standards was $50 \mu \mathrm{L}$. The column temperature was maintained at $30^{\circ} \mathrm{C}$ using an oven (Shimadzu CTO-20AC, Rydalmere, NSW, Australia). The mobile phase contained water: acetonitrile: formic acid, 95:4:1 (v:v:v) (Mobile Phase A) and acetonitrile (Mobile Phase B). The flow rate of the solvents was $1 \mathrm{~mL} / \mathrm{min}$ and the following gradient solution was used: $0 \mathrm{~min} 5 \% \mathrm{~B} ; 15 \mathrm{~min}, 20 \% \mathrm{~B} ; 35 \mathrm{~min}, 100 \% \mathrm{~B} ; 40$ $\min , 5 \% \mathrm{~B} ; 50 \mathrm{~min}, 50 \% \mathrm{~B}$. The analysis was stopped after $60 \mathrm{~min}$. The system was equilibrated between runs for 10 min using $5 \% \mathrm{~B}$.

Rutin content was calculated from the peak area of $280 \mathrm{~nm}$ by the external standard method, using a calibration curve $\left(\mathrm{R}^{2}=0.999\right)$. Rutin standards were prepared by dissolving standard compounds in methanol at a concentration of $200 \mu \mathrm{g} / \mathrm{mL}$. The results were expressed as $\mathrm{mg} / \mathrm{g} \mathrm{dw}$.

\section{Antioxidant capacity}

\section{Cupric Reducing Antioxidant Capacity (CUPRAC) assay}

CUPRAC assay was determined as described by Papoutsis et al. [21]. Briefly, $1 \mathrm{~mL}$ of $\mathrm{CuCl}_{2}(10 \mathrm{mM})$ was mixed with $1 \mathrm{~mL}$ of neocuproine $(7.5 \mathrm{mM})$ and $1 \mathrm{~mL}$ of $\mathrm{NH}_{4} \mathrm{Ac}(\mathrm{pH} 7.0)$. Then, $1.1 \mathrm{~mL}$ of sample was added to this mixture. The mixture was left at ambient temperature for $1.5 \mathrm{~h}$ before the absorbance was measured at $450 \mathrm{~nm}$ using a UV spectrophotometer (Varian 
Australia Pty. Ltd., Vic., Melbourne, Australia). The results were expressed as mg Trolox equivalents per g of sample dry weight (mg TE/g dw).

\section{2,2-Diphenyl-1-picrylhydrazyl (DPPH) assay}

DPPH assay was determined as described by Papoutsis et al. [21]. A stock solution was prepared by dissolving $24 \mathrm{mg} \mathrm{DPPH}$ in $100 \mathrm{~mL}$ methanol and then stored at $-20{ }^{\circ} \mathrm{C}$ until use. For the preparation of working solution $10 \mathrm{~mL}$ of stock solution were mixed with $45 \mathrm{~mL}$ methanol to obtain an absorbance of $1.1 \pm 0.02$ at $515 \mathrm{~nm}$. Subsequently, $2.85 \mathrm{~mL}$ of working solution were mixed with $0.15 \mathrm{~mL}$ of sample and left under darkness at room temperature for 30 min before measuring the absorbance at $515 \mathrm{~nm}$ using a UV spectrophotometer (Varian Australia Pty. Ltd., Vic., Melbourne, Australia). The results were expressed as mg Trolox equivalents per $\mathrm{g}$ of sample dry weight (mg TE/g dw).

\section{Ferric Reducing Antioxidant Power (FRAP) assay}

FRAP assay was determined as described by Papoutsis et al. [21]. A working FRAP solution was prepared by mixing $300 \mathrm{mM}$ acetate buffer with $10 \mathrm{mM}$ TPTZ (2,4,6-tripyridyls-triazine) in $40 \mathrm{mM} \mathrm{HCl}$ and $20 \mathrm{mM} \mathrm{FeCl}_{3}$ in the ratio of 10:1:1. The working solution was warmed at $37{ }^{\circ} \mathrm{C}$ in a water bath (Ratek Instruments Pty. Ltd., Boronia,Vic., Australia). Subsequently, $2.85 \mathrm{~mL}$ of FRAP working solution was mixed with $0.15 \mathrm{~mL}$ of sample and incubated at room temperature in the dark for 30 min before its absorbance was measured at 593 nm using a UV spectrophotometer (Varian Australia Pty. Ltd., Vic., Melbourne, Australia). $\mathrm{dw})$. 

applying three different extraction techniques (optimized HWE, optimized AUAE and OSCE) using ZEISS SIGMA VP microscope. Freeze dried lemon by-product was used as a control. After extraction lemon residues were dried at $60{ }^{\circ} \mathrm{C}$ until constant weight. Samples were gold coated before the images were taken using a secondary electron detector. Trying to avoid the charging issue, we used backscatter detector in case of AUAE residues.

\section{Statistical analysis}

In the optimization experiment, each run was conducted in triplicate and the results were expressed as mean \pm standard deviation. JMP software (version 11) was applied to design and optimize the conditions for the AUAE of TPC and rutin from lemon by-product. The effect of different factors on TPC yields in the preliminary experiments was investigated by one-way ANOVA and Duncan's post hoc multiple comparison test, using SPSS statistical software (version 23, IBM, Crop., NY, USA) at $P<0.05$. The $t$-test was employed for the comparison of the predicted TPC and rutin values with the observed ones $(P<0.05)$. The comparison of the different extraction methods was performed by one-way ANOVA, and the Duncan's post hoc multiple comparison test was employed for the determination of significance among the different means, at a significance level of $P<0.05$. Before ANOVA application the assumptions of: i) homogeneity of variances (using Levene's test) and ii) normal distribution of variables (using Shapiro-Wilk test) were evaluated and satisfied. Each extraction run and analysis was performed in triplicate. The Pearson's correlation test was employed for the determination of correlation coefficients among TPC, TF and antioxidant assays at $P<0.01$.

\section{Results and discussion}

\section{Preliminary experiments}


Five preliminary experiments were conducted before optimization, for monitoring the

effect of individual parameters on TPC and rutin yields and the results can be seen in Table 1.

The effect of three different particle sizes was examined in the preliminary experiment 1 since particle size is considered as an important parameter affecting the recovery yields of polyphenols from plant tissues $[24,25]$. The results showed that as the particle size increased from $1.40 \mathrm{~mm}$ to $2.00 \mathrm{~mm}$ the TPC yields significantly decreased $(P<0.05)$. However, higher rutin yields were achieved with the particle sizes of 2.00 and $1.40 \mathrm{~mm}$. These results are in agreement with Lee et al. [25] who found that the recovery yields of two polymethoxyflavonoids (nobiletin and tangeretin) increased when the particle size of orange peel decreased. The higher TPC yields obtained by the smaller particle size could be due to the larger surface area being exposed to water and ultrasonic power, facilitating a higher mass transfer of analytes from dried lemon by-products to water. The particle size of $1.40 \mathrm{~mm}$ was thus selected for the next preliminary and optimization experiments since with this particle size, high TPC and rutin yields were achieved. In the second preliminary experiment, the effect of extraction time was examined. As the extraction time increased from 30 to 40 min the recovery yields of TPC significantly increased and then levelled off $(P<0.05)$ (Table 1$)$. These results are in agreement with Dahmoune et al. [11] who mentioned that extraction time significantly affected the recovery of TPC from lemon by-products under ultrasound-assisted extraction. However, the extraction time employed in the previous study was shorter than in the present experiment. The difference in the extraction time between the two studies could be attributed to the different solvents that were used. It has been previously mentioned that the mixture of ethanol with water leads to higher recovery yields of polyphenols from plant tissues compared to pure water in shorter time [26]. The organic solvent may facilitate the extraction of polyphenols by enhancing the collapse of cell walls and diffusion of polyphenols to the solvent. Extraction time had no effect on rutin yields $(P>0.05)$, however, an extraction time 
greater than 40 min seems to negatively affect rutin recovery. Therefore, an extraction time ranging between 35-45 min was selected for the optimization experiment. In the third preliminary experiment, the effect of extraction temperature was investigated. The recovery yields of TPC and rutin increased when the extraction temperature increased from $23{ }^{\circ} \mathrm{C}$ (ambient temperature) to 50 and $40{ }^{\circ} \mathrm{C}$, respectively $(P<0.05)$ (Table 1$)$. Higher extraction temperatures might lead to higher recovery yields of TPC and rutin by increasing their solubility and weakening cell wall structure by enhancing the activity of some enzymes [27]. Therefore, an extraction temperature ranging between $45-55{ }^{\circ} \mathrm{C}$ was selected for the optimization experiment. In the fourth preliminary experiment, the effect of ultrasonic power was examined. Ultrasonic power had no effect on either TPC or rutin yields, at the operating conditions that were applied (extraction time of $20 \mathrm{~min}$ and temperature of $\left.30{ }^{\circ} \mathrm{C}\right)(P>0.05)$ (Table 1). However, ultrasonic power ranging between 150 and $250 \mathrm{~W}$ was used for optimization, since interactions with other extraction parameters may occur and affect the extraction yields of TPC and rutin. Finally, in the fifth preliminary experiment, the effect of sample-to-solvent ratio on TPC and rutin yields were examined. Sample-to-solvent ratio significantly affected the recovery yields of TPC $(P<0.05)$, while it did not affect rutin yields $(P>0.05)$. As the sample-to-solvent ratio increased from $1 \mathrm{~g} / 100 \mathrm{~mL}$ to $4 \mathrm{~g} / 100 \mathrm{~mL}$ the TPC significantly decreased and then levelled off (Table 1). These findings are in agreement with a previous study which mentioned that the recovery yields of some phenolic compounds from Citrus reticulata fruit increased as the sample-to-solvent ratio decreased until an optimum level, and then levelled off [28]. When a lower sample-to-solvent ratio is used, an increase in the diffusion ratio is observed, due to a greater concentration gradient [29]. Considering solvent consumption, the ratio of $2 \mathrm{~g} / 100 \mathrm{~mL}$ was selected for the optimization experiments. 


\section{Optimization of aqueous ultrasound-assisted extraction (AUAE) conditions for the} recovery of TPC and rutin from lemon by-products

The prediction model for TPC was significant $(P<0.05)$ with a non-significant lack of fit $(P>0.05)$ and a low RMSE value (0.11), implying that the model adequately fits the data and can be used for prediction. This observation was further supported by the actual vs predicted plot (Fig. 2A), where the points are close to the fitted line. The coefficient of multiple determination $\left(\mathrm{R}^{2}\right)$ was 0.90 , implying that $90 \%$ of the variation was explained by the model (Fig. 2A). The predicted optimum AUAE conditions for TPC were obtained by using the prediction profiler and the surface plots and were: extraction time of $45 \mathrm{~min}$, extraction temperature of $50{ }^{\circ} \mathrm{C}$ and ultrasonic power of $250 \mathrm{~W}$ with the predicted value of $18.10 \pm 0.24 \mathrm{mg}$ GAE/g dw. For validating the accuracy of the model the extraction was performed at the optimum conditions and the observed value for TPC was $17.97 \pm 0.21 \mathrm{mg} \mathrm{GAE} / \mathrm{g} \mathrm{dw}$ which was not significantly different from the predicted value $(P>0.05)$ (Table 2$)$.

The effect of different parameters on TPC yields can be seen in Table 3 and Fig. 2B (Pareto plot). Ultrasonic power and extraction time had a significant positive linear effect on TPC of lemon by-products $(P<0.05)$ (Table 3$)$, implying that higher yields of TPC can be achieved by increasing ultrasonic power and extraction time (Fig. 3). The positive effect of ultrasonic power and extraction time on the recovery of phenolic compounds has been previously reported $[30,11]$. However, these results are in contrast with our preliminary experiments, where ultrasonic power did not affect the TPC yields. This difference could be attributed to: i) the shorter extraction time (20 min) and ii) lower extraction temperature (30 ${ }^{\circ} \mathrm{C}$ ) used in the preliminary experiments when the effect of ultrasonic power was examined, compared to the optimization trials. Extraction temperature had a significant negative quadratic effect $(P<0.05)$ on TPC yields (Table 3 and Fig. 2B, Pareto plot), implying that an extraction temperature higher than the optimum, results in the decrease of TPC yields. Although the Folin 
349 Ciocalteu assay may have the interference of ascorbic acid for the quantification of total 350 phenols, our results suggest that the degradation of cell walls may increase as the temperature increases, resulting in the release of both phenolic compounds and enzymes implicated in polyphenol oxidation. At the same time, the activity of the released enzymes (i.e. peroxidase, polyphenol oxidase) implicated in polyphenol degradation might be enhanced by the temperature applied [31,12], leading to lower polyphenol yields. Although the interaction between temperature and ultrasonic power was not significant $(P>0.05)$, from Pareto plot (Fig. 2B), it could be concluded that the interaction between temperature and ultrasonic power may negatively affect TPC yields. Considering that the interaction between temperature and power negatively affected the antioxidant capacity of extracts measured by DPPH (Fig. 2E, Pareto plot), it could be concluded that increasing both temperature and power, some phenolic compounds with antiradical capacity might be degraded because of thermal oxidation and/or scavenging of free radicals created due to the ultrasonic power. Ma et al. [32] reported that increasing simultaneously both temperature and power, some phenolic compounds with antiradical capacity might be degraded because of thermal oxidation and/or scavenging of free radicals created due to ultrasonic power. On the other hand, the interaction between temperature and power positively affected rutin yields (Fig. 2D, Pareto plot) and antioxidant capacity measured by CUPRAC (Fig. 2F, Pareto plot), implying that the recovery of phenolic compounds exhibiting reducing potency can be enhanced by increasing both temperature and power.

The prediction model for rutin yields was significant $(P<0.05)$ with a non-significant lack of fit $(P>0.05)$ and a low RMSE value of 0.05 , implying that the model adequately fits the data and can be used for prediction. This observation was further supported by the actual vs predicted plot (Fig. 2C), where the points are close to the fitted line. The coefficient of multiple determination $\left(\mathrm{R}^{2}\right)$ was 0.90 , implying that $90 \%$ of the variation was explained by the model 
(Fig. 2C). The predicted optimum AUAE conditions for rutin were obtained by using the prediction profiler and the surface plots and were: extraction time of $35 \mathrm{~min}$, extraction temperature of $48^{\circ} \mathrm{C}$ and ultrasonic power of $150 \mathrm{~W}$ with the predicted value of $3.20 \pm 0.12 \mathrm{mg} / \mathrm{g}$ dw. For validating the accuracy of the model the extraction was performed at the optimum conditions and the observed value for rutin was $3.13 \pm 0.03 \mathrm{mg} / \mathrm{g} \mathrm{dw}$, which was not significantly different from the predicted value $(P>0.05)$ (Table 2$)$.

The effect of different parameters on rutin yields can be seen in Table 3 and Fig. 2D (Pareto plot). Extraction temperature had a significant negative quadratic effect $(P<0.05)$ on rutin yields, implying rutin degradation at temperatures higher than the optimum. A similar trend was observed in the preliminary experiment where the rutin yield increased as the extraction temperature increased until an optimum point and then levelled off. These findings are in agreement with Ma et al. [32] who showed that temperature is a sensitive variable for extracting polyphenols from citrus using ultrasound-assisted extraction. The interaction between temperature and power had a significant positive effect on rutin yields $(P<0.05)$, implying that aqueous extracts with high rutin content could be achieved by increasing simultaneously extraction temperature and ultrasonic power (Fig. 3). Extraction time and power might negatively affect rutin yields, since both parameters had a non-significant negative linear effect on rutin recovery $(P>0.05)$ (Table 3 and Fig. 2D, Pareto plot), implying rutin degradation probably due to the free radical formation which is promoted by high ultrasound power in aqueous solutions [15].

\section{Comparison between different extraction methods}

The TPC of the extracts obtained by AUAE was not significantly different compared to those obtained by HWE and OSCE $(P>0.05)$ (Table 4). However, extracts obtained by HWE showed higher TF than those achieved by AUAE and OSCE $(P<0.05)$ (Table 4). High 
temperature leads to higher polyphenol yields by enhancing the solubility of bioactive compounds, as well as by increasing the diffusion of compounds from plant matrix into the solvent [33]. The lower TF values of extracts obtained by AUAE could be explained by the reaction of some flavonoids with the free radicals produced in the aqueous solution due to the ultrasonic power [15], since flavonoids act as hydrogen donors and singlet oxygen quenchers due to their high redox potential [34], which could be attributed to the low bond dissociation enthalpy of the phenolic O-H group [35]. In case of OSCE, the lower TPC and TF values could be attributed to: i) the degradation of some phenolic compounds to extended extraction time, and ii) the reduced diffusion of polyphenols from the dried lemon by-product to the solvent, because of dehydration and collapse of lemon by-product cells [36].

Two different assays (CUPRAC and FRAP) were used for the comparison of the antioxidant capacity of the extracts, since different reactions between polyphenols and antioxidant assays may take place. CUPRAC assays both hydrophilic and lipophilic antioxidants, while FRAP mainly assays hydrophilic antioxidants [37]. Extracts obtained by HWE exhibited the highest antioxidant capacity measured by both CUPRAC and FRAP (Table 4). The lower antioxidant capacity of extracts obtained by AUAE and OSCE could be attributed to the lower flavonoid content in these extracts since a high correlation between $\mathrm{TF}$ and antioxidant assays was observed (Table 4). HWE was a more efficient technique for the recovery of hydrophilic compounds with ferric reducing antioxidant power compared to AUAE.

SEM analysis was employed for observing the morphology of lemon by-product residues after applying the three extraction techniques, and the images showed that all the extraction methods led to cell damage to a different extent (Fig. 4). OSCE caused cell wall destruction, dehydration and shrinkage (Fig. 4C) in comparison with the freeze dried by-product which was not subjected to extraction where no destruction was observed (Fig. 4A). Fig. 4B shows that 
424 HWE resulted in a disruption of the cell walls of lemon by-product which could be due to the denaturation of cell wall membranes [38]. According to a previous study, dried lemon residues are resistant to ultrasound energy [11]. However, in this study, a cell wall damage was observed in the lemon residues after AUAE (Fig. 4D). This difference could be due to the higher extraction temperatures applied in this study, as well as to the different physical parameters of the solvents that were employed. High extraction temperatures might lead to the weakening of cell walls by enhancing the activity of some enzymes [27], facilitating cell wall damage due to cavitation phenomena. Moreover, high temperatures can increase the number of cavitation bubbles facilitating greater cell wall disruption [23].

Overall, HWE and AUAE extractions required shorter extraction time than the OSCE method for the preparation of extracts with high polyphenol content and antioxidant capacity. Indeed, OSCE required less solvent volume than the two other extraction techniques. However, some disadvantages of organic solvent use should be taken into consideration in the selection of the extraction method, including: i) toxicity of organic solvent for human health and environment, ii) solvent purchase and disposal costs, iii) special storage requirements, and iv) solvent residues in the final product. Therefore, from an economical and environmental point of view, both HWE and AUAE, should be considered for the preparation of high-quality polyphenol extracts from lemon by-products.

\section{Conclusions}

A Box-Behnken design was effectively employed for optimizing the recovery of TPC and rutin from lemon by-products. The recovery of TPC was positively affected by the ultrasonic power and extraction time (linear effect), while extraction temperature had a negative quadratic effect on TPC yields. Rutin recovery was mainly affected by the interaction between extraction temperature and ultrasonic power (positive effect) and extraction 
temperature (negative quadratic effect). HWE resulted in extracts with higher TF and

450

451

452

453

454

455

456

457

458

459

460

461

462

463

464

465

466

467

468

469

470

471

472

473

474

475

antioxidant capacity compared to AUAE and OSCE, in a considerably shorter time. Comparing AUAE with the OSCE, it could be concluded that AUAE could be effectively employed for the recovery of polyphenols from lemon by-products, since, it leads in shorter time to extracts with approximately the same TPC, TF and antioxidant capacity, compared to those obtained by OSCE. SEM analysis showed that all the extraction methods led to a cell damage to a different extent.

Acknowledgements The authors would like to thank the staff of Electron Microscope and XRay Unit (EMX) for their support in SEM analysis. We also thank Mick Lentini at Eastcoast Food and Beverages for the supply of the lemon waste.

\section{Compliance with ethical standards}

Funding This research was supported by the University of Newcastle and Australian Research Council (ARC) Training Centre for Food and Beverage Supply Chain Optimisation (IC140100032). NSW Department of Primary Industries is a partner organisation in the Training Centre.

Conflict of interest statement The authors declare no conflict of interest.

Compliance with ethics requirements Research does not involve any human participants and/or animal.

\section{Reference}

1. FAO (2016) Intergovernmental Group on Citrus Fruits. A Subsidiary Body of the FAO Committee on Commodity Problems (CCP) Rome. http://www.fao.org/3/a-i5558e.pdf. Accessed 03.01.2017. 

from different citrus processes as a source of customized functional fibres. Food Chem 100:736-741. 3. González-Molina E, Domínguez-Perles R, Moreno DA, García-Viguera C (2010) Natural bioactive compounds of Citrus limon for food and health. J Pharm Biomed Anal 51:327-345. 4. Lou SN, Lai YC, Hsu YS, Ho CT (2016) Phenolic content, antioxidant activity and effective compounds of kumquat extracted by different solvents. Food Chem 197, Part A:1-6.

5. Arcas MC, Botía JM, Ortuño AM, Del Río JA (2000) UV irradiation alters the Levels of flavonoids involved in the defence mechanism of Citrus aurantium fruits against Penicillium digitatum. Eur J Plant Pathol 106:617-622.

6. Ortuño A, Báidez A, Gómez P, Arcas MC, Porras I, García-Lidón A, Río JAD (2006) Citrus paradisi and Citrus sinensis flavonoids: Their influence in the defence mechanism against Penicillium digitatum. Food Chem 98:351-358.

7. Wang L, Wang J, Fang L, Zheng Z, Zhi D, Wang S, Li S, Ho CT, Zhao H (2014) Anticancer activities of citrus peel polymethoxyflavones related to angiogenesis and others. Biomed Res Int 2014. doi: $10.1155 / 2014 / 453972$

8. Yang J, Guo J, Yuan J (2008) In vitro antioxidant properties of rutin. LWT-Food Sci Technol 41:1060-1066.

9. Kamel KM, Abd El-Raouf OM, Metwally SA, Abd El-Latif HA, El-sayed ME (2014) Hesperidin and rutin, antioxidant citrus flavonoids, attenuate cisplatin-induced nephrotoxicity in rats. J Biochem Mol Toxicol 28:312-319.

10. Khoddami A, Wilkes MA, Roberts TH (2013) Techniques for Analysis of Plant Phenolic Compounds. Molecules 18:2328-2375.

11. Dahmoune F, Boulekbache L, Moussi K, Aoun O, Spigno G, Madani K (2013) Valorization of Citrus limon residues for the recovery of antioxidants: Evaluation and optimization of microwave and ultrasound application to solvent extraction. Ind Crops Prod 50:77-87.

12. Abad-García B, Berrueta LA, López-Márquez DM, Crespo-Ferrer I, Gallo B, Vicente F (2007) Optimization and validation of a methodology based on solvent extraction and liquid chromatography for the simultaneous determination of several polyphenolic families in fruit juices. J Chromatogr A 1154:87-96.

13. Robards K, Antolovich M (1997) Analytical chemistry of fruit bioflavonoidsA Review. Analyst $122(2): 11 \mathrm{R}-34 \mathrm{R}$.

14. Chemat F, Zille H, Khan MK (2011) Applications of ultrasound in food technology: Processing, preservation and extraction. Ultrason Sonochem 18:813-835.

15. Riesz P, Berdahl D, Christman CL (1985) Free radical generation by ultrasound in aqueous and nonaqueous solutions. Environ Health Perspect 64:233-252.

16. Espada-Bellido E, Ferreiro-González M, Carrera C, Palma M, Barroso CG, Barbero GF (2017) Optimization of the ultrasound-assisted extraction of anthocyanins and total phenolic compounds in mulberry (Morus nigra) pulp. Food Chem 219 (Supplement C):23-32.

17. Bezerra MA, Santelli RE, Oliveira EP, Villar LS, Escaleira LA (2008) Response surface methodology (RSM) as a tool for optimization in analytical chemistry. Talanta 76:965-977.

18. Baş D, Boyacı İH (2007) Modeling and optimization I: Usability of response surface methodology. J Food Eng 78:836-845.

19. Vera Candioti L, De Zan MM, Cámara MS, Goicoechea HC (2014) Experimental design and multiple response optimization. Using the desirability function in analytical methods development. Talanta 124:123-138.

20. Nwabueze TU (2010) Review article: Basic steps in adapting response surface methodology as mathematical modelling for bioprocess optimisation in the food systems. Int J Food Sci Tech 45:17681776.

21. Papoutsis K, Pristijono P, Golding JB, Stathopoulos CE, Bowyer MC, Scarlett CJ, Vuong QV (2016) Optimisation of aqueous extraction conditions for the recovery of phenolic compounds and antioxidants from lemon pomace. Int J Food Sci Tech 51:2009-2018.

22. Papoutsis K, Pristijono P, Golding JB, Stathopoulos CE, Bowyer MC, Scarlett CJ, Vuong QV (2017) Effect of vacuum-drying, hot air-drying and freeze-drying on polyphenols and antioxidant capacity of lemon (Citrus limon) pomace aqueous extracts. Int J Food Sci Tech 52:880-887. 

Ultrasound assisted extraction of food and natural products. Mechanisms, techniques, combinations, protocols and applications. A review. Ultrason Sonochem 34:540-560. 24. Luthria DL (2008) Influence of experimental conditions on the extraction of phenolic compounds from parsley (Petroselinum crispum) flakes using a pressurized liquid extractor. Food Chem 107:745752.

25. Lee YH, Charles AL, Kung HF, Ho CT, Huang TC (2010) Extraction of nobiletin and tangeretin from Citrus depressa Hayata by supercritical carbon dioxide with ethanol as modifier. Ind Crops Prod 31:59-64.

26. Galván D’Alessandro L, Dimitrov K, Vauchel P, Nikov I (2014) Kinetics of ultrasound assisted extraction of anthocyanins from Aronia melanocarpa (black chokeberry) wastes. Chem Eng Res Des 92:1818-1826.

27. Ma X, Zhang L, Wang W, Zou M, Ding T, Ye X, Liu D (2016) Synergistic effect and mechanisms of combining ultrasound and pectinase on pectin hydrolysis. Food Bioproc Tech 9:1249-1257.

28. Sun Y, Wang J, Gu S, Liu Z, Zhang Y, Zhang X (2010) Simultaneous determination of flavonoids in different parts of Citrus reticulata 'Chachi' fruit by high performance liquid chromatographyphotodiode array detection. Molecules 15:5378-5388.

29. Cacace JE, Mazza GJ (2003) Mass transfer process during extraction of phenolic compounds from milled berries. J Food Eng 59:379-389.

30. Ma Y, Ye X, Hao Y, Xu G, Xu G, Liu D (2008) Ultrasound-assisted extraction of hesperidin from penggan (Citrus reticulata) peel. Ultrason Sonochem 15:227-232.

31. Mizobutsi GP, Finger FL, Ribeiro RA, Puschmann R, Neves LLdM, Mota WFd (2010) Effect of $\mathrm{pH}$ and temperature on peroxidase and polyphenoloxidase activities of litchi pericarp. Sci Agr 67:213217.

32. Ma YQ, Chen JC, Liu DH, Ye XQ (2009) Simultaneous extraction of phenolic compounds of citrus peel extracts: effect of ultrasound. Ultrason Sonochem 16:57-62.

33. Pinelo M, Rubilar M, Jerez M, Sineiro J, Núñez MJ (2005) Effect of solvent, temperature, and solvent-to solid ratio on the total phenolic content and antiradical activity of extracts from different components of grape pomace. J Agric Food Chem 53:2111-2117.

34. Ignat I, Volf I, Popa IV (2011) A critical review of methods for characterisation of polyphenolic compounds in fruits and vegetables. Food Chem 126:1821-1835.

35. Rappoport Z (2004) The Chemistry of Phenols, 2 Volume Set. John Wiley \& Sons

36. Garcia-Castello EM, Rodriguez-Lopez AD, Mayor L, Ballesteros R, Conidi C, Cassano A (2015) Optimization of conventional and ultrasound assisted extraction of flavonoids from grapefruit (Citrus paradisi L.) solid wastes. LWT-Food Sci Technol 64:1114-1122.

37. Apak R, Güçlü K, Demirata B, Özyürek M, Çelik S, Bektaşoğlu B, Berker K, Özyurt D (2007) Comparative evaluation of various total antioxidant capacity assays applied to phenolic compounds with the CUPRAC assay. Molecules 12: 1496-1547.

38. Al-Farsi MA, Lee CY (2008) Optimization of phenolics and dietary fibre extraction from date seeds. Food Chem 108:977-985. 
Table 1. Effect of single factors (particle size of sample ( $\mathrm{mm})$, extraction time (min), extraction temperature $\left({ }^{\circ} \mathrm{C}\right)$, ultrasonic power $(\mathrm{W})$ and sample-to-solvent ratio $(\mathrm{g} / \mathrm{mL})$ on total phenolic content (TPC) and rutin of lemon (Citrus limon L.) by-product aqueous extracts. Data are expressed as mean \pm standard deviation $(\mathrm{n}=3)$.

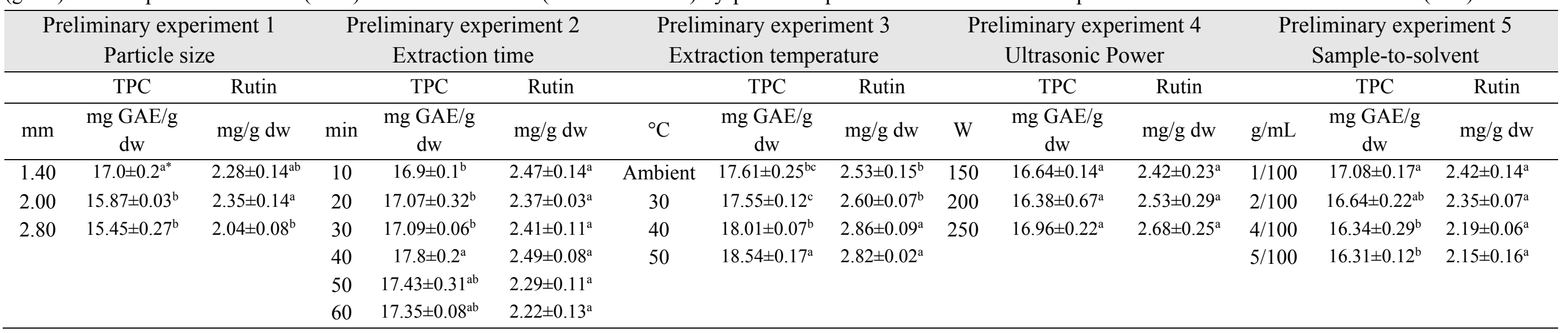

*Values followed by different superscript letter within the same column are significantly different at $P<0.05$, according to ANOVA and Duncan's test. 
Table 2. Box-Behnken design and results for total phenolic content (TPC), rutin and antioxidant capacity (measured by CUPRAC and DPPH) of lemon (Citrus limon L.) by-product aqueous extracts. Data are expressed as mean \pm standard deviation $(n=3)$. Validation of the predicted values for TPC and rutin.

\begin{tabular}{|c|c|c|c|c|c|c|c|c|}
\hline \multirow[t]{4}{*}{ Run } & \multirow[t]{3}{*}{ Pattern } & \multirow{2}{*}{\multicolumn{3}{|c|}{$\begin{array}{l}\text { Experimental conditions } \\
\text { Independent variables }\end{array}$}} & \multirow{2}{*}{\multicolumn{4}{|c|}{$\begin{array}{l}\text { Experimental results } \\
\text { Dependent variables }\end{array}$}} \\
\hline & & & & & & & & \\
\hline & & $\begin{array}{l}\text { Extraction } \\
\text { time }\end{array}$ & $\begin{array}{l}\text { Extraction } \\
\text { temperature }\end{array}$ & $\begin{array}{c}\text { Ultrasonic } \\
\text { power }\end{array}$ & TPC & Rutin & CUPRAC & DPPH \\
\hline & & $\min$ & ${ }^{\circ} \mathrm{C}$ & $\mathrm{W}$ & $\mathrm{mg}$ GAE$/ \mathrm{g} \mathrm{dw}$ & $\mathrm{mg} / \mathrm{g} \mathrm{dw}$ & $\mathrm{mg} \mathrm{TE} / \mathrm{g} \mathrm{dw}$ & $\mathrm{mg} \mathrm{TE} / \mathrm{g} \mathrm{dw}$ \\
\hline 1 & ++0 & 45 & 55 & 200 & $17.75 \pm 0.18$ & $3.03 \pm 0.16$ & $40.78 \pm 0.16$ & $0.119 \pm 0.003$ \\
\hline 2 & $0-+$ & 40 & 45 & 250 & $17.76 \pm 0.32$ & $2.86 \pm 0.17$ & $40.05 \pm 0.07$ & $0.108 \pm 0.002$ \\
\hline 3 & 000 & 40 & 50 & 200 & $17.71 \pm 0.11$ & $3.14 \pm 0.06$ & $41.3 \pm 0.2$ & $0.110 \pm 0.006$ \\
\hline 4 & --0 & 35 & 45 & 200 & $17.62 \pm 0.16$ & $3.01 \pm 0.01$ & $40.59 \pm 0.28$ & $0.114 \pm 0.003$ \\
\hline 5 & 000 & 40 & 50 & 200 & $17.67 \pm 0.07$ & $3.17 \pm 0.04$ & $41.43 \pm 0.45$ & $0.111 \pm 0.006$ \\
\hline 6 & $-0-$ & 35 & 50 & 150 & $17.63 \pm 0.04$ & $3.17 \pm 0.06$ & $40.31 \pm 0.23$ & $0.118 \pm 0.002$ \\
\hline 7 & -+0 & 35 & 55 & 200 & $17.30 \pm 0.02$ & $3.03 \pm 0.06$ & $40.01 \pm 0.38$ & $0.115 \pm 0.002$ \\
\hline 8 & +0 & 45 & 50 & 150 & $17.6 \pm 0.2$ & $3.10 \pm 0.13$ & $39.94 \pm 0.48$ & $0.112 \pm 0.002$ \\
\hline 9 & +-0 & 45 & 45 & 200 & $17.69 \pm 0.11$ & $2.98 \pm 0.01$ & $41.13 \pm 0.36$ & $0.113 \pm 0.003$ \\
\hline 10 & $0++$ & 40 & 55 & 250 & $17.64 \pm 0.14$ & $3.16 \pm 0.05$ & $41.72 \pm 0.01$ & $0.118 \pm 0.002$ \\
\hline 11 & 0-- & 40 & 45 & 150 & $17.2 \pm 0.1$ & $3.15 \pm 0.09$ & $40.47 \pm 0.78$ & $0.095 \pm 0.006$ \\
\hline 12 & 000 & 40 & 50 & 200 & $17.82 \pm 0.11$ & $3.14 \pm 0.03$ & $41.12 \pm 0.25$ & $0.109 \pm 0.003$ \\
\hline 13 & $+0+$ & 45 & 50 & 250 & $18.07 \pm 0.29$ & $3.16 \pm 0.02$ & $41.5 \pm 0.2$ & $0.111 \pm 0.001$ \\
\hline 14 & $0+-$ & 40 & 55 & 150 & $17.62 \pm 0.13$ & $3.04 \pm 0.05$ & $41.10 \pm 0.36$ & $0.117 \pm 0.003$ \\
\hline 15 & $-0+$ & 35 & 50 & 250 & $17.76 \pm 0.44$ & $3.21 \pm 0.09$ & $41.38 \pm 0.64$ & $0.117 \pm 0.002$ \\
\hline
\end{tabular}

Validation of the predicted values

\begin{tabular}{lll}
\hline Dependent Variables & $\begin{array}{l}\text { Predicted } \\
\text { values }\end{array}$ & $\begin{array}{l}\text { Observed } \\
\text { values }\end{array}$ \\
\hline TPC $(\mathrm{mg} \mathrm{GAE} / \mathrm{g} \mathrm{dw})$ & $18.10 \pm 0.24^{\mathrm{a}^{*}}$ & $17.97 \pm 0.21^{\mathrm{a}}$ \\
Rutin $(\mathrm{mg} / \mathrm{g} \mathrm{dw})$ & $3.20 \pm 0.12^{\mathrm{a}}$ & $3.13 \pm 0.03^{\mathrm{a}}$ \\
\hline
\end{tabular}

\footnotetext{
*Values followed by the same superscript letter at the same row are not significantly different at $P<0.05$, according to $t$ test.
} 
Table 3. Regression coefficients of the fitted polynomial equation (Eq. (1)) for total phenolic content and rutin content of lemon (Citrus limon L.) by-product aqueous extracts.

\begin{tabular}{|c|c|c|c|c|c|c|c|c|}
\hline \multirow{2}{*}{ Regression coefficients } & \multicolumn{4}{|c|}{ Total phenolic content } & \multicolumn{4}{|c|}{ Rutin content } \\
\hline & Estimate & Sum of squares & F-value & $P$-value & Estimate & Sum of squares & F-value & $P$-value \\
\hline Intercept & 17.733333 & & & & 3.1511898 & & & \\
\hline \multicolumn{9}{|l|}{ Linear effect } \\
\hline Time & 0.1025 & 0.08405 & 7.3321 & $0.0424^{*}$ & -0.017141 & 0.00235040 & 0.9302 & 0.3791 \\
\hline Temperature & 0.005 & 0.00020 & 0.0174 & 0.9001 & 0.031052 & 0.00771381 & 3.0530 & 0.1410 \\
\hline Ultrasonic power & 0.145 & 0.16820 & 14.6729 & $0.0122 *$ & -0.007649 & 0.00046805 & 0.1852 & 0.6848 \\
\hline \multicolumn{9}{|l|}{ Quadratic effect } \\
\hline Time $\times$ Time & 0.0358333 & 0.00474 & 0.4136 & 0.5485 & -0.014099 & 0.00073401 & 0.2905 & 0.6130 \\
\hline Temperature $\times$ Temperature & -0.179167 & 0.11853 & 10.3395 & $0.0236^{*}$ & -0.124214 & 0.05696874 & 22.5473 & $0.0051^{*}$ \\
\hline Ultrasonic power $\times$ power & 0.0008333 & 0.00000256 & 0.0002 & 0.9886 & 0.0248608 & 0.00228206 & 0.9032 & 0.3856 \\
\hline \multicolumn{9}{|l|}{ Interaction effect } \\
\hline Time $\times$ Temperature & 0.095 & 0.03610 & 3.1492 & 0.1361 & 0.0083893 & 0.00028152 & 0.1114 & 0.7521 \\
\hline Time $\times$ Ultrasonic power & 0.08 & 0.02560 & 2.2332 & 0.1953 & 0.0040648 & 0.00006609 & 0.0262 & 0.8778 \\
\hline Temperature $\times$ Ultrasonic power & -0.135 & 0.07290 & 6.3594 & 0.0531 & 0.1013224 & 0.04106493 & 16.2528 & $0.0100^{*}$ \\
\hline
\end{tabular}

*Significance at $P<0.05$. 
Table 4. Comparison of three different extraction methods (aqueous ultrasound-assisted extraction (AUAE), hot water extraction (HWE) and organic solvent conventional extraction (OSCE) ) in terms of TPC, TF and antioxidant capacity (measured by CUPRAC and FRAP) of lemon by-products (Citrus limon L.). Data are expressed as mean \pm standard deviation $(n=3)$.

\begin{tabular}{lllll}
\hline Extraction method & TPC & TF & CUPRAC & FRAP \\
\hline & $\mathrm{mg} \mathrm{GAE} / \mathrm{g} \mathrm{dw}$ & $\mathrm{mg} \mathrm{CE} / \mathrm{g} \mathrm{dw}$ & $\mathrm{mg} \mathrm{TE} / \mathrm{g} \mathrm{dw}$ & $\mathrm{mg} \mathrm{TE} / \mathrm{g} \mathrm{dw}$ \\
\hline AUAE & $17.97 \pm 0.21^{\mathrm{ab} *}$ & $4.85 \pm 0.03^{\mathrm{b}}$ & $40.73 \pm 0.48^{\mathrm{c}}$ & $9.4 \pm 0.3^{\mathrm{b}}$ \\
HWE & $18.3 \pm 0.4^{\mathrm{a}}$ & $5.45 \pm 0.06^{\mathrm{a}}$ & $46.31 \pm 0.72^{\mathrm{a}}$ & $10.83 \pm 0.26^{\mathrm{a}}$ \\
OSCE & $16.96 \pm 0.55^{\mathrm{b}}$ & $5.11 \pm 0.13^{\mathrm{b}}$ & $43.74 \pm 1.37^{\mathrm{b}}$ & $9.23 \pm 0.05^{\mathrm{b}}$
\end{tabular}

\section{Correlation}

$\begin{array}{lll}\text { CUPRAC } & r=0.36, P=0.342 & r=0.86, P=0.003 \\ \text { FRAP } & r=0.66, P=0.05 & r=0.87, P=0.002\end{array}$

*Values followed by different superscript letter within the same column are significantly different at $P<0.05$, according to ANOVA and Duncan's test. 


\section{Figure captions}

Fig. 1. Experimental design of the experiment.

Fig. 2. A) Actual vs predicted plot for total phenolic content (TPC), B) Pareto plot for TPC, C) Actual vs predicted plot for rutin, D) Pareto plot for rutin, E) Pareto plot for antioxidant capacity measured by DPPH, F) Pareto plot for antioxidant capacity measured by CUPRAC.

Fig. 3. A) Surface plot for the effect of extraction temperature $\left({ }^{\circ} \mathrm{C}\right)$ and time $(\mathrm{min})$ on total phenolic content (TPC), B) Surface plot for the effect of extraction temperature $\left({ }^{\circ} \mathrm{C}\right)$ and ultrasonic power (W) on TPC, C) Surface plot for the effect of ultrasonic power (W) and extraction time (min) on TPC, D) Surface plot for the effect of extraction temperature $\left({ }^{\circ} \mathrm{C}\right)$ and time (min) on rutin yields, E) Surface plot for the effect of ultrasonic power (W) and extraction time (min) on rutin yields, F) Surface plot for the effect of extraction temperature $\left({ }^{\circ} \mathrm{C}\right)$ and ultrasonic power $(\mathrm{W})$ on rutin yields.

Fig. 4. Scanning electron microscopy (SEM) images of A) freeze dried lemon by-product without extraction, B) freeze dried lemon by-product after hot water extraction, C) freeze dried lemon by-product after organic solvent conventional extraction, and D) freeze dried lemon byproduct after aqueous ultrasound-assisted extraction. 
Lemon pomace

Freeze dried powder

Preliminary experiment 1

Effect of particle size $(1.40,2.00 \& 2.80 \mathrm{~mm})$

Extraction conditions:

- Sample-to-solvent $/ \mathrm{g} / \mathrm{l} 00 \mathrm{~mL}$,

- Ultrasonic power $150 \mathrm{~W}$,

- Extraction time $20 \mathrm{~min}$,

- Extraction temperature $30^{\circ} \mathrm{C}$

Parameters for determination: Total phenolic content (TPC) \& rutin

Preliminary experiment 2

Effect of extraction time $(10,20,30,40,50 \& 60 \mathrm{~min})$

Extraction conditions:

- Particle size (preliminary 1),

- Sample-to-solvent $1 \mathrm{~g} / 100 \mathrm{~mL}$,

- Ultrasonic power $150 W$,

- Extraction temperature $30^{\circ} \mathrm{C}$

Parameters for determination: TPC \& rutin

Preliminary experiment 3

Effect of extraction temperature (ambient $\left(23^{\circ} \mathrm{C}\right), 30,40 \& 50^{\circ} \mathrm{C}$ )

Extraction conditions:

- Particle size (preliminary 1),

- Sample-to-solvent $1 \mathrm{~g} / 100 \mathrm{~mL}$,

- Ultrasonic power $150 \mathrm{~W}$,

- Extraction time $20 \mathrm{~min}$

Parameters for determination: TPC \& rutin

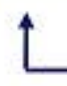

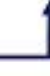

Comparison

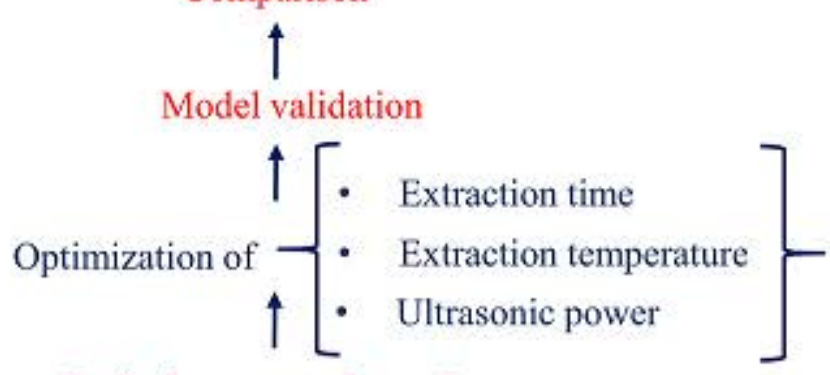

Using RSM Box-Behnken design for TPC and Rutin

Preliminary experiment 5

Effect of sample-to-solvent (1/100, 2/100, 4/100 \& 5/100)

Extraction conditions:

- Particle size (preliminary 1),

- Ultrasonic power $150 \mathrm{~W}$,

- Extraction time $20 \mathrm{~min}$,

- Extraction temperature $30^{\circ} \mathrm{C}$

Parameters for determination: TPC \& rutin

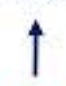

Preliminary experiment 4

Effect of ultrasonic power $(150,200 \& 250 \mathrm{~W})$

Extraction conditions:

- Particle size (preliminary 1)

- Sample-to-solvent $1 \mathrm{~g} / 100 \mathrm{~mL}$,

- Extraction time $20 \mathrm{~min}$,

- Extraction temperature $30^{\circ} \mathrm{C}$

Parameters for determination: TPC \& rutin 


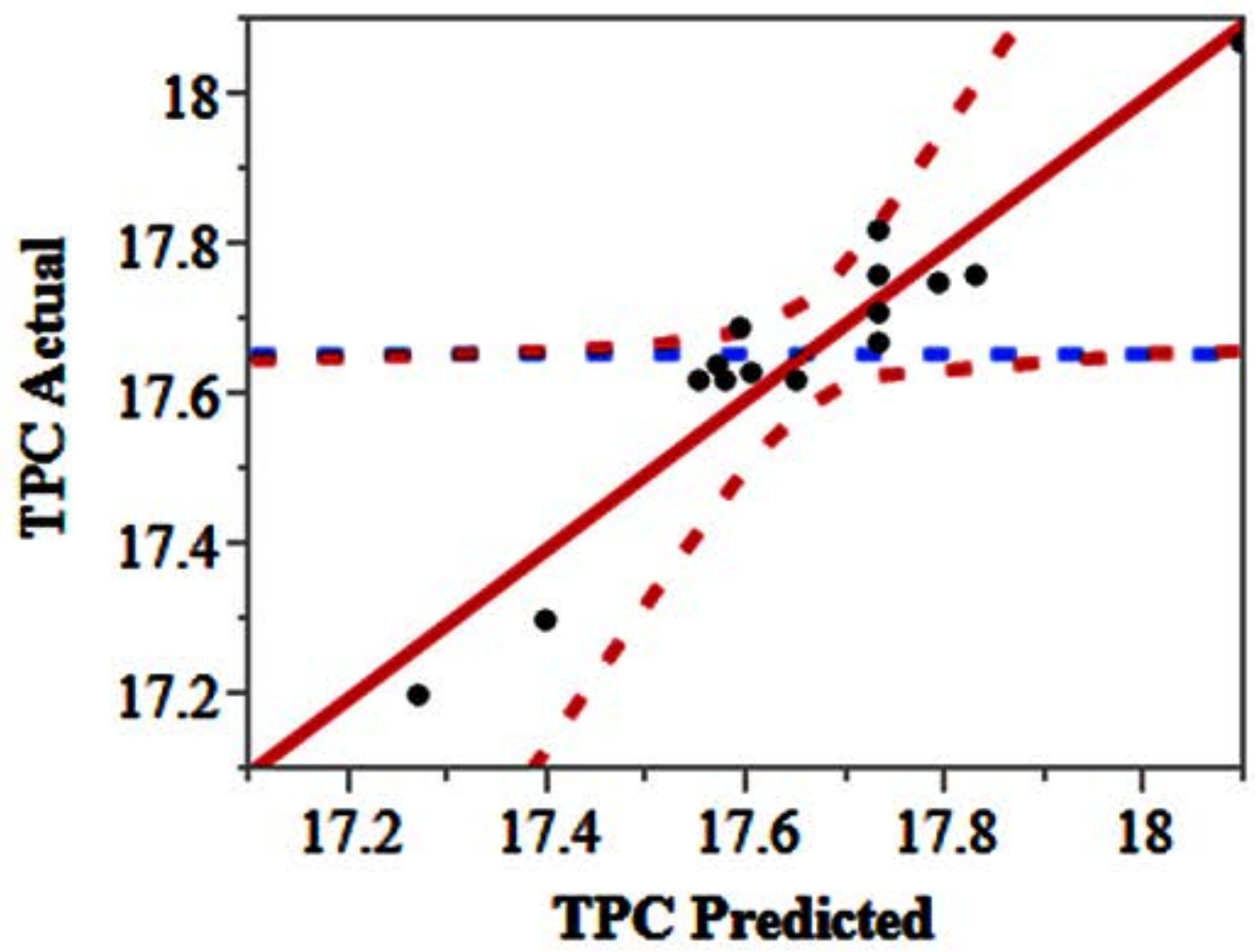

$\mathrm{R}^{2}=0.90 ; \quad \mathrm{R}^{2} \quad$ adjusted $=0.72 ; \quad P$-value of model $=0.0457$; Lack of fit $=0.2985 ; \mathrm{RMSE}=0.11$ 


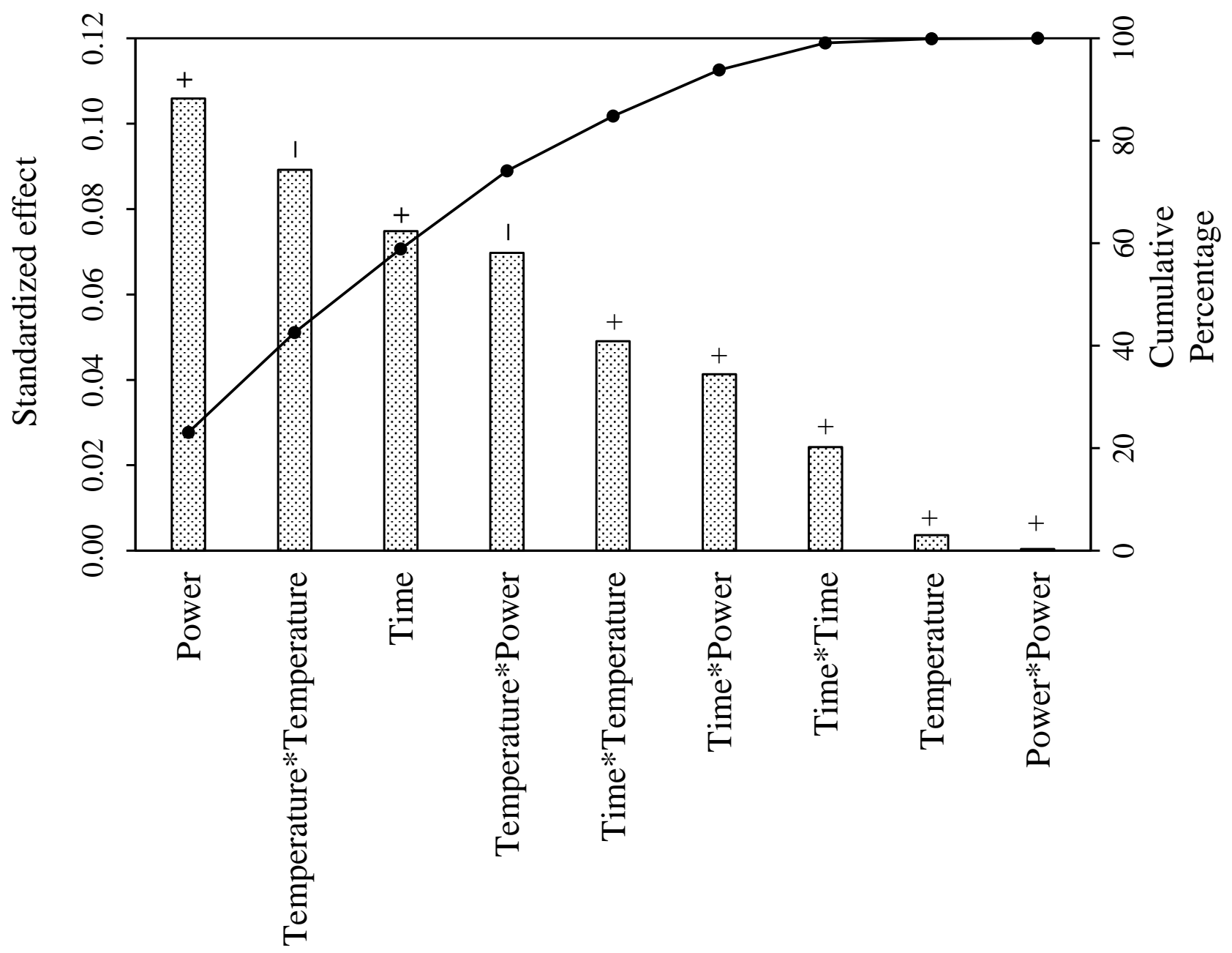

Figure 2B 


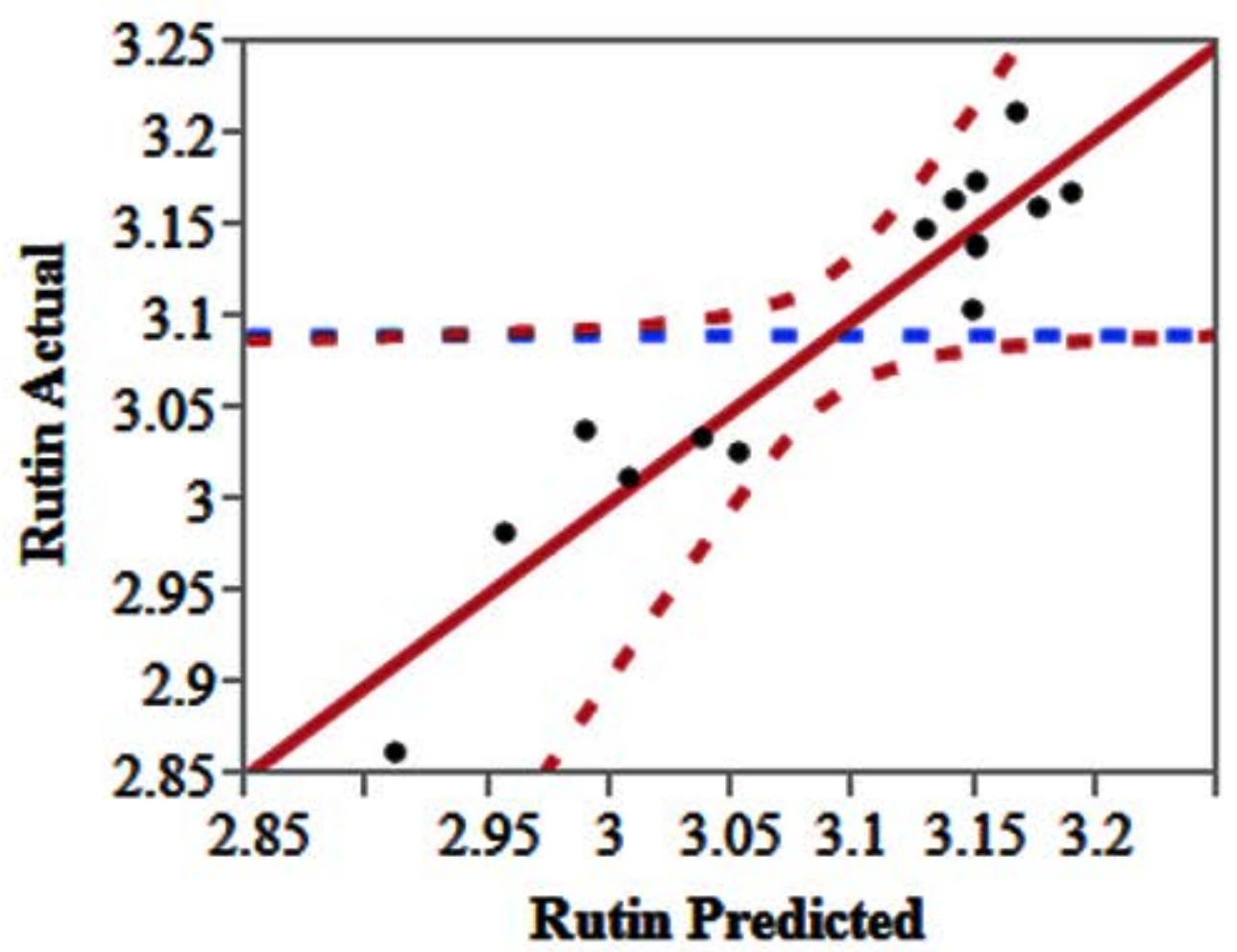

$\mathrm{R}^{2}=0.90 ; \quad \mathrm{R}^{2} \quad$ adjusted $=0.72 ; \quad P$-value $\quad$ of model $=0.0457$; Lack of fit $=0.0978 ;$ RMSE $=0.05$ 


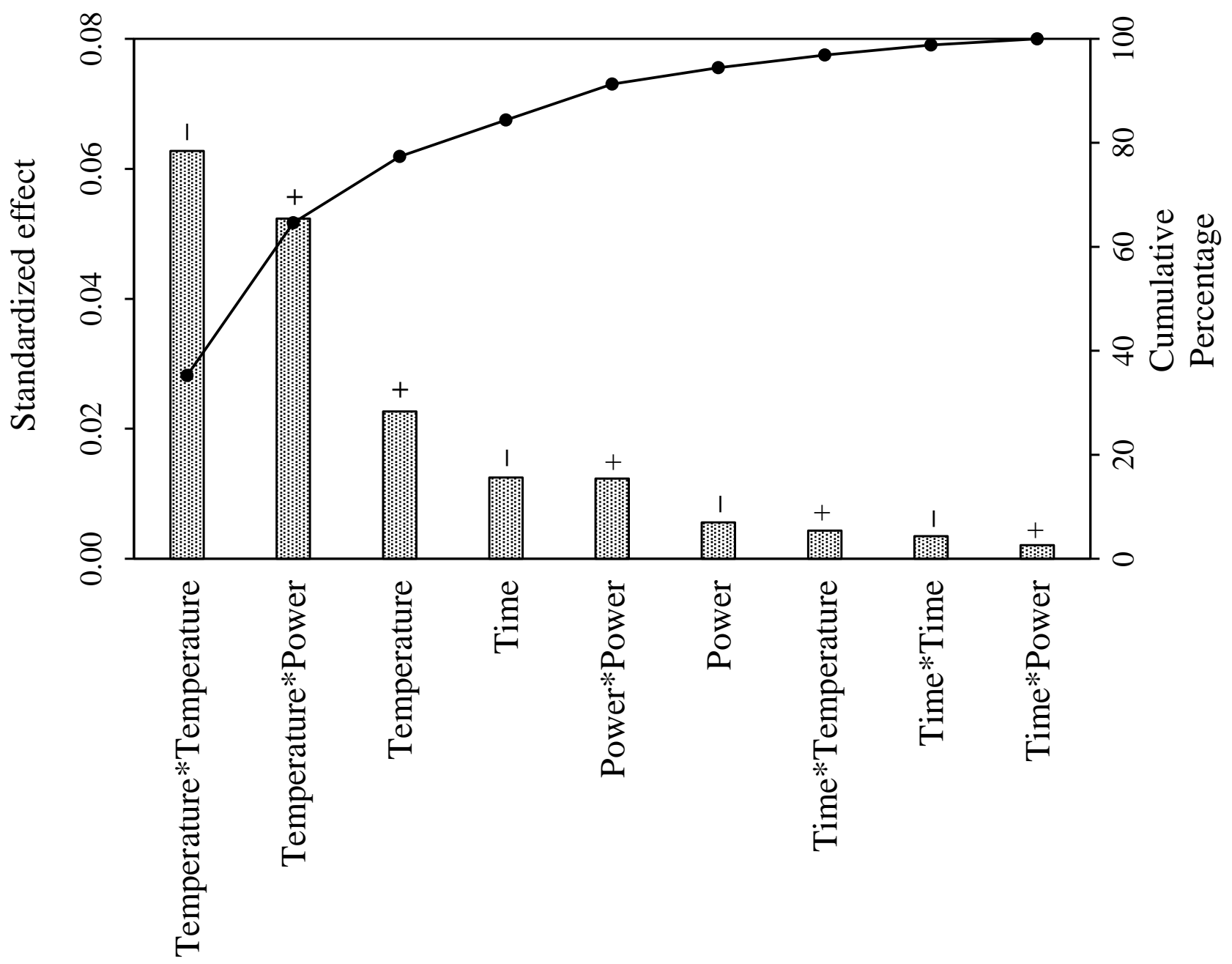

Figure 2D 


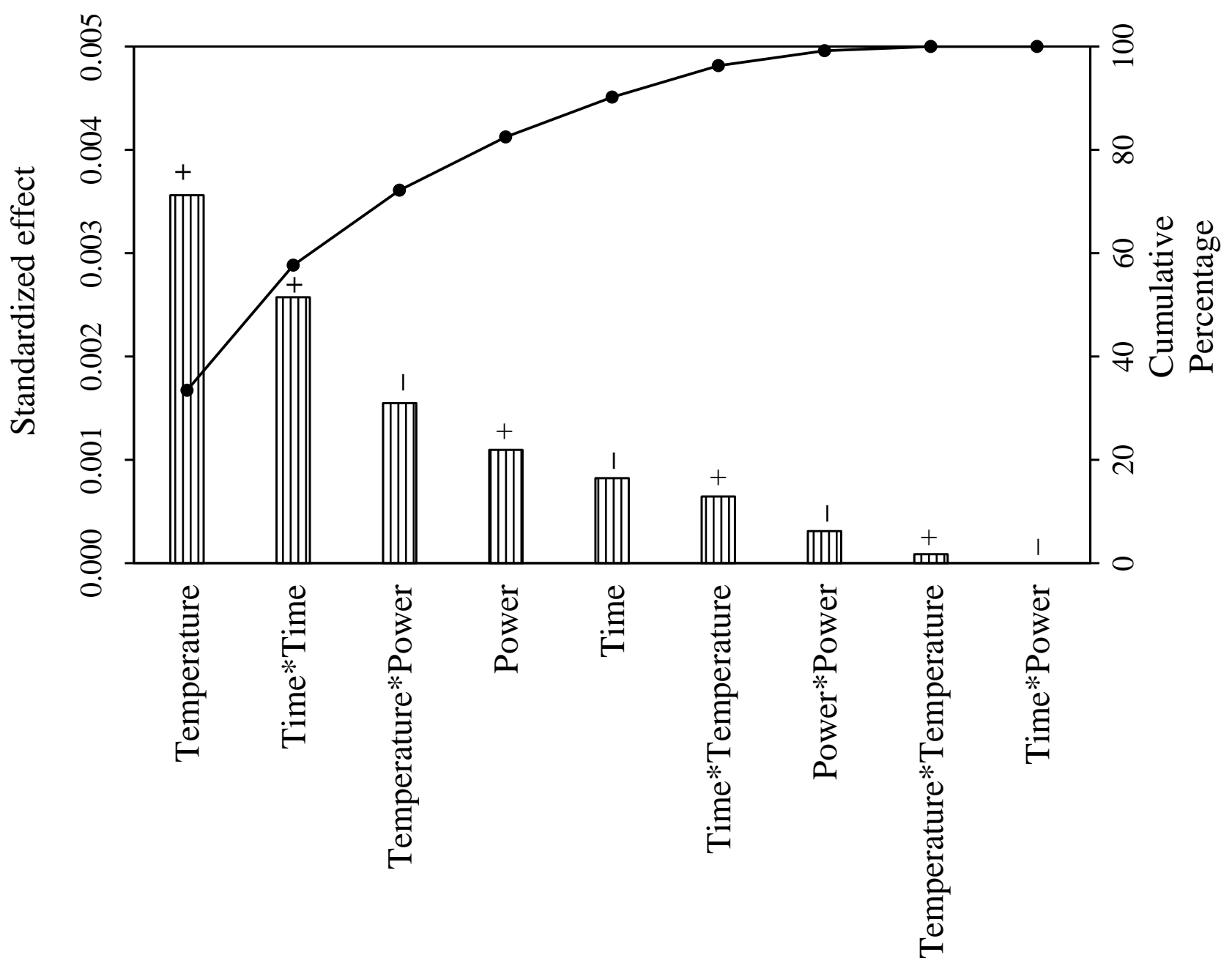

Figure 2E 


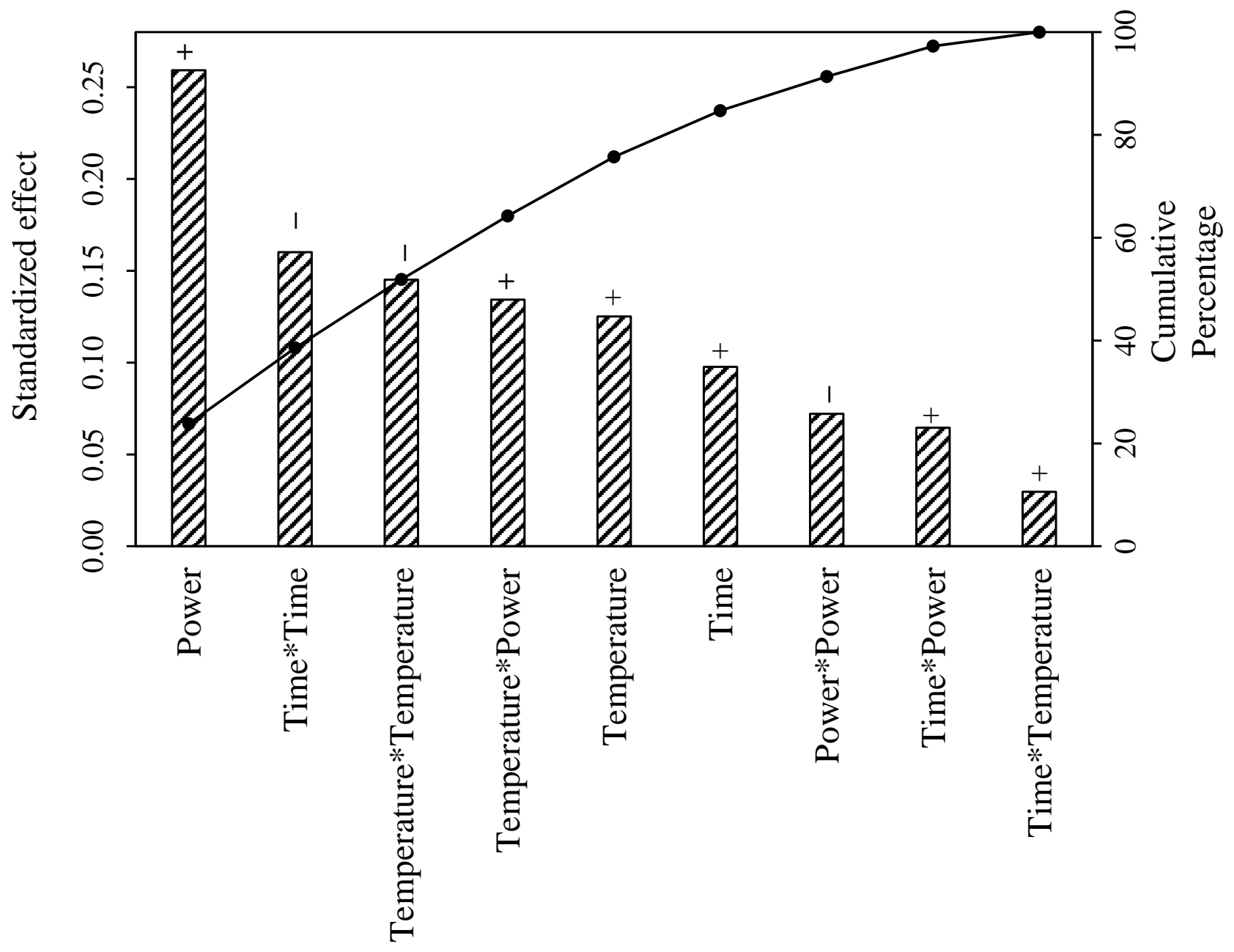

Figure 2F 


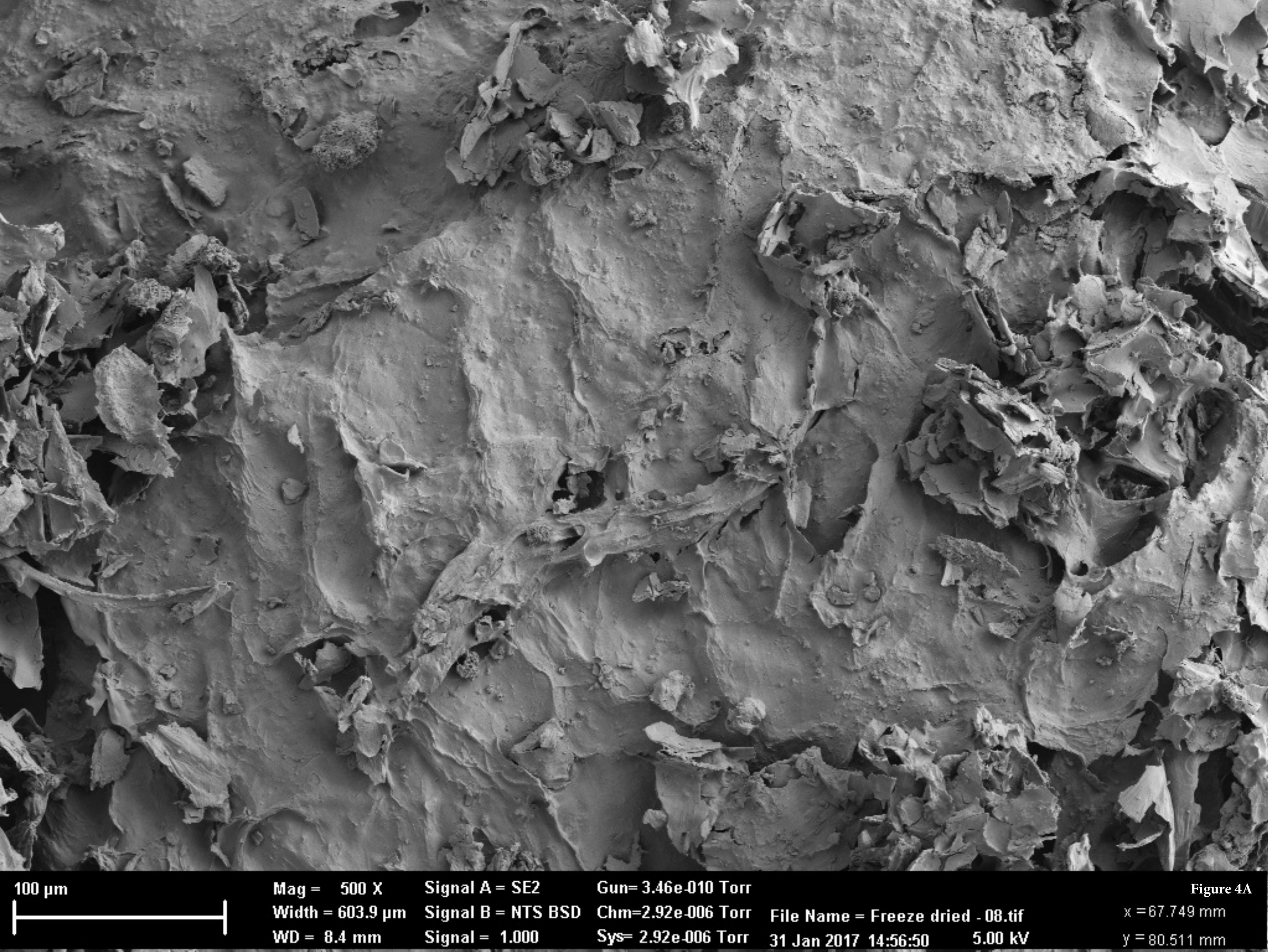




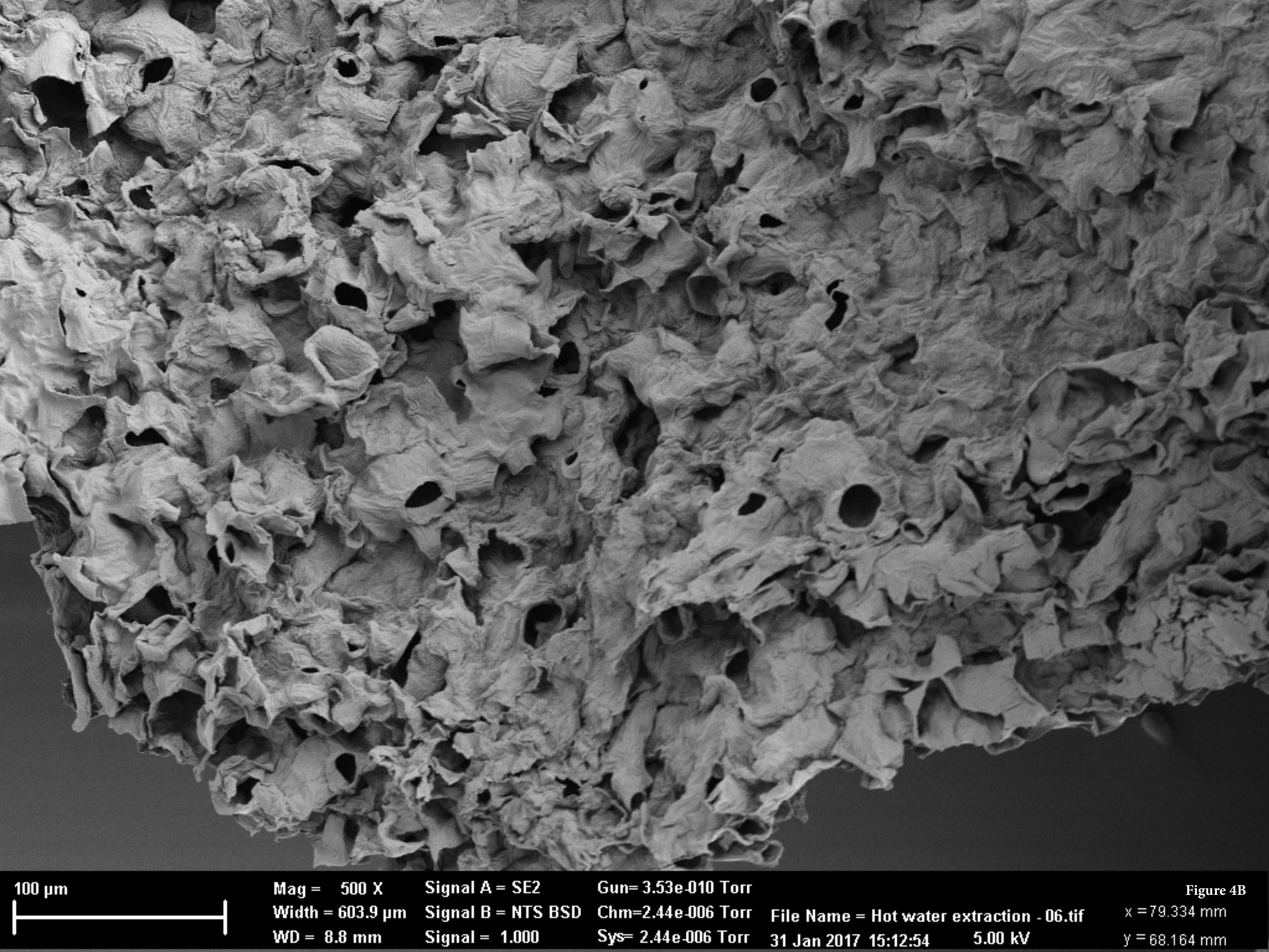




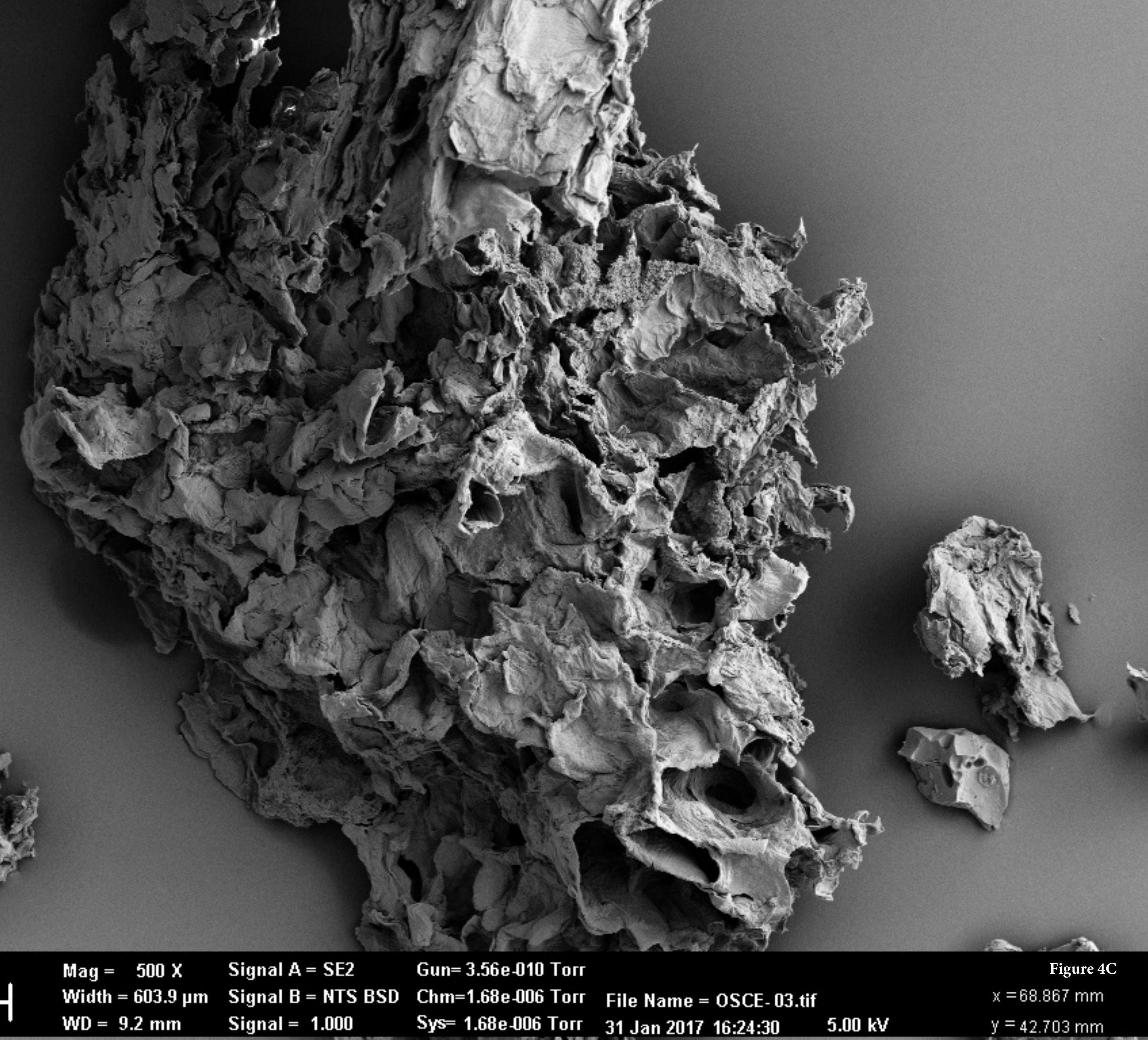




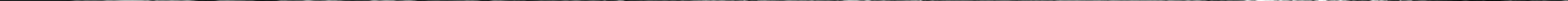

